\title{
The Relationship between Reading Strategy Use and EFL Test Performance
}

\author{
Saraswati Dawadi
}

\begin{abstract}
There has been a steady interest in investigating the relationship between strategy use and English as a foreign language (EFL) test performance. Despite numerous studies on strategy use, the relationship between the two is still not clear. This paper reports on a study that investigated the use of reading strategies in the Secondary Education Examination English reading test and the relationship between reading strategy use and the test performance. A sample of 312 EFL learners studying at Grade 10 in Nepal participated in this study. They were asked to take the test and then respond to a reading strategy questionnaire. The quantitative software SPSS (version 20) was used to analyze the data. The results indicated that participants were active strategy users, and they used cognitive strategies more frequently than metacognitive strategies. A significant relationship was identified between reading strategy use and EFL proficiency; high-proficiency learners reported significantly higher use of reading strategies than moderate-proficiency learners, who in turn reported higher use of those strategies than their low-proficiency peers. Implications of these findings for EFL teaching and recommendations for further research are discussed.
\end{abstract}

Keywords: English as a foreign language, Cognitive reading strategy, Metacognitive reading strategy, Proficiency

Reading is "a cognitive process in which readers interact with the text, forming hypothesis, predictions and using their background knowledge to construct the meaning" (Sungatullina, Zalyaeva, \& Gorelova, 2016, p.2). It can be seen as a constructive process in which readers, texts, and contexts interact with each other. It is very much an individual, complex cognitive process - what Bernhardt (1991) has called "an intrapersonal problemsolving task" (p. 6). Therefore, performance variation in a second language
(L2) reading test occurs due to learners' individual differences (Cohen \& Upton, 2007).

It is usually argued that low-proficiency learners and high-proficiency learners process information differently and use different strategies to understand a reading text. Zhang, Aryadoust and Zhang (2014) claim, "skilled readers are distinguished from unskilled readers by their conscious awareness of strategic reading processes and their actual use of reading strategies" 
(p.77). Additionally, Cummins (2000) argues that learners need to develop a certain level of proficiency in the target language in order to be able to read a text effectively. Therefore, it seems important to explore strategy types that L2 learners with different linguistic proficiency use to interact with a text, and how strategy choices influence their performance.

Bachman and Palmer (2010), having highlighted the role of strategy use on L2 learning, present a framework and elaborate two sets of learners' characteristics: focal and peripheral attributes. Focal attributes refer to learners' language proficiency, which involves language knowledge (including grammatical, textual, sociolinguistic and functional) and strategic competence - the "higher-order metacognitive strategies that provide a management function in language use" (p.48). Peripheral attributes refer to test-takers' personal attributes including cognitive strategies which refer to the ways in which test-takers "execute plans in actual language use" (p.35).

Cognitive strategies refer to the strategies that require specific actions and goaloriented cognitive steps that learners invoke when reading an L2 text. They are ongoing conscious mental behaviours used by L2 learners to perform better in the language. They are, according to Phakiti (2008), composed of three strategies: comprehending (understanding a text, identifying main ideas in the text and making inferences), memory (storing information), and retrieval (recalling information, such as relating the information from a text to prior knowledge, guessing meanings from a context, and applying grammatical rules). Beside these cognitive strategies, L2 learners also seem to use metacognitive strategies to understand a text.

Metacognitive strategies refer to some cognitive steps that L2 learners take to monitor or regulate their cognitive processes when reading a text. They are grouped into three broad categories: planning, monitoring and evaluation (Zhang, et al., 2014). Each of these is considered in turn. Planning strategies are test-takers' actions of previewing or overviewing a task and making decisions about how or when the task should be done and the order of steps to be taken to accomplish the task. They also involve setting a speed at which the task should be done in order to be able to accomplish the task within the limited time frame. This in turn supports learners to perform the task successfully (Yayli, 2010). Monitoring strategies refer to test-takers' deliberate actions to monitor their own performance and to ensure that tasks are properly executed; these strategies are used for "checking and regulating performance" (Zhang, Goh, \& Kunnan, 2014, p.78), whereas evaluation strategies are the strategies that L2 learners use to reflect on or respond in some way to a reading task. The learners use these strategies to check or evaluate how well they have completed the task.

\section{Literature Review}

There has been a steady interest in investigating the relationship between strategy use and L2 test performance (e.g Cohen \& Upton, 2007; Phakiti, 2003, 2008; Purpura, 1997,1998; Song and Cheng, 2006; Zhang, et al., 2014; Zhang, Liu, Zhao and Xie, 2011). Some studies support a connection between strategy use and L2 test performance, while others do not. I will 
illustrate the current state of related research with key examples.

Phakiti (2003) examined the relationship between cognitive and metacognitive strategy use and reading performance on an EFL reading comprehension test. In the study, 384 English as a foreign language (EFL) learners responded to a reading strategy questionnaire after they took an EFL reading test. Then, eight of the learners (four highly successful and four unsuccessful) took part in a retrospective interview. The results indicated a positive relationship between cognitive and metacognitive strategy use and the test performance, and highly successful testtakers "reported significantly higher use of metacognitive strategy than the moderately successful ones who in turn reported higher use of these strategies than the unsuccessful test-takers" (p.26). Likewise, Zhang and Zhang (2013) found that high-proficiency learners use more and multiple strategies to facilitate reading comprehension relative to low-proficiency learners in the Chinese context. Having reported similar results about the Chinese EFL learners, Aryadoust and Zhang (2016) further argued that learners' with higherproficiency use reading strategies more frequently than the students with lowerproficiency. Additionally, Sungatullina, Zalyaeva, and Gorelova (2016) established a connection between success in an EFL reading test and the degree of students' metacognitive awareness and strategy use.

However, there are other studies around the globe which report little or no connection between strategy use and L2 test performance. For instance, unlike the findings of Zhang and Zhang (2013), Purpura (1997, 1999) reported that lowproficiency EFL learners use more strategies than the high-proficiency learners. Among the 15 strategy types included in the questionnaire, the high-proficiency group reported using only five strategies (inferencing, linking with prior knowledge, monitoring, self-evaluating and practicing naturalistically) more frequently than the low-proficiency group; all other strategies were reportedly used more frequently by the low-proficiency group. The results revealed that neither cognitive nor metacognitive strategy use had a direct effect on the test performance. Similarly, Ghaemi and Ghaemi (2011) also found no significant relationship between strategy use and an EFL reading comprehension test performance in the Iranian context. Similarly, Dawadi's (2015) study on the use of reading strategies on the School Leaving Certificate (SLC) reading test revealed that both successful and unsuccessful testtakers used similar strategies to respond to the test. She argued that successful completion of a test depends on how strategically L2 test-takers can use reading strategies, but not necessarily what or how many strategies the test-takers use. However, her major focus was only on cognitive strategies use and the test validation, not on the strategy use and the test performance.

As discussed above, an extensive body of research has investigated the relationship between strategy use and L2 reading test performance. However, what is still a moot point is whether strategy use enhances L2 test performance (Zhang, et al., 2014). Additionally, almost no research has explored how Nepalese EFL learners respond to the Secondary Education Examination (SEE) reading test - a national level test conducted at the end of 10-year secondary school education in Nepal. Thus, this study was conducted to 
investigate current beliefs about the links between reading strategy use and EFL test performance, and also to investigate the reading strategies used in the SEE English reading test.

\section{Research Questions}

The study addresses the following three research questions:

1. What type of reading strategies are used in the SEE English reading test?

2. Are there any significant differences between high-proficiency, moderateproficiency and low-proficiency testtakers in the use of reading strategies?

3. What relationships, if any, exist between reading strategy use and the test performance?

\section{Participants}

A total of 325 (male=172, female=153) EFL learners studying at grade 10 in Nepal participated in the study. They were randomly selected from seven public secondary schools in Nepal. Their age ranged between 14 and 17 years $(M=15.13$, $\mathrm{SD}=.68)$. All of them were Nepali native speakers, who had learned English for an average of 11.36 years $(S D=1.45)$. At the time of the data collection, they were preparing for the SEE.

\section{Instruments}

Two different instruments were used in the study: a reading test and a questionnaire. Participants were asked to take a reading test (one of the SEE reading tests of the academic year 2015-2016) and based on their test scores, they were divided into three groups: high-proficiency (74), moderate-proficiency (151) and lowproficiency (87). Following Phakiti (2003), students who obtained $70 \%$ or above, between 46 and $69 \%$ and below $45 \%$ on the test score were grouped as 'highproficiency', 'moderate-proficiency' and 'low-proficiency' students, respectively.

The questionnaire was adapted from Phakiti (2008) as the questionnaire in Phikiti's study was designed for EFL learners. As a result, it seemed very appropriate for the participants in this study. However, it was translated into Nepali, which participants were comfortable with or most proficient in. It was translated back to English to cross check whether the translation caused any distortions in the intended meaning. It consisted of 30 cognitive and metacognitive strategy items designed on a 5-point Likert scale: 1 (never), 2 (rarely), 3 (sometimes), 4 (often), and 5 (always) (See Appendix A). Then, it was piloted with 10 students studying at Grade 10 in a public school in Nepal to ensure instruction clarity and content appropriacy.

\section{Data Collection, Scoring, and Preparation}

After obtaining their consents, participants were asked to take the test first and then fill out the questionnaire. It was ensured that they had not practiced the test before they were asked to take it as part of the study. Each student's responses to the test items were scored. Each answer was marked and double-checked to ensure that each item was scored accurately. Then, the scores along with the responses to the questionnaire were entered into the IBM SPSS Statistics Version 20 software for further analysis. 
Several statistical procedures were routinely carried out with each data set, whether it involved item level analysis or sub/scale level analysis, to ensure reliability of the findings. First, descriptive statistics were examined at item level (the means, standard deviation, skewness, and kurtosis) to obtain how participants reported using these strategies and to ensure that all values of skewness and kurtosis were within the accepted range ( \pm 2 ) for a normal distribution (Zhang \& Zhang, 2013). Then, internal consistency reliability estimates were computed for the strategy variables both at scale and subscale levels. The overall reliability coefficient (á $=0.882$ ) ensured the general reliability of the study. The internal reliability coefficients (Cronbach's alpha) for the two main categories (scales) and their subscales are presented in Table 1.

Table 1. Taxonomy of cognitive and metacognitive strategies
Then, the patterns of strategy choice at individual and sub/scale levels were analyzed by examining the means and the standard deviations within the whole group. Then, a factorial ANOVA test was conducted to examine whether the mean differences between the three groups were statistically significant. In order to examine students' strategy use in terms of the Likert scale that ranges from 1 to 5, following Zhang (2009), this study employed three levels of usages, that is, high (mean of 3.5 or higher), moderate (mean of 2.5 to 3.4 ), and low (mean of 2.4 or lower). Finally, a regression test was conducted to examine the relationship between strategy use and EFL proficiency.

\section{Results}

The results indicated that participants frequently used many of the available reading strategies. On the whole, they

\begin{tabular}{|l|l|c|l|c|}
\hline Processing & Subscale & No. of items & Items & Reliability \\
\hline Cognitive strategies & Comprehending & 4 & $7,8,9,10$ & 0.310 \\
& Memory & 4 & $11,12,13,14$ & 0.503 \\
& Retrieval & 5 & $15,16,17,18,19$ & 0.722 \\
& Sub total & 13 & & 0.780 \\
\hline Metacognitive strategies & Planning & 6 & $1,2,3,4,5,6$ & 0.570 \\
& Monitoring & 5 & $20,21,22,23,24$ & 0.646 \\
& Evaluating & 6 & $25,26,27,28,29,30$ & 0.520 \\
& Sub total & 17 & & 0.811 \\
\hline & Total & 30 & & 0.882 \\
\hline
\end{tabular}

re porte dly
used the
a v i l a b l e
$\mathrm{r}$ e a d i g
strategies at a
$\mathrm{h}$ i $\mathrm{g}$ h
frequency rate
$(\mathrm{M}=3.502, \mathrm{SD}$
$=\quad 0.632)$.
Among the 30
str a te g i e s
included in the
questionnaire,

$18(60 \%)$ fell

The reliabilities of the subscale level of the questionnaire, as indicated in the above table, varied from .310 to .722 . Considering the fact that there were relatively few items in the subscales, following Zhang and Zhang (2013), it was decided to keep all of them for further analysis. into the high usage level ( $\left.\mathrm{M} \mathrm{e}^{\prime \prime} 3.5\right)$ and 10 $(33.33 \%)$ fell into the medium usage level (M e" 2.5). However, two of them (6.66\%) fell into the low usage level ( $\left.\mathrm{M} \mathrm{d}^{\prime \prime} 2.4\right)$.

Closer inspection of the data at item level reveals an interesting picture. Among the 
five most frequent strategies, three of them (Items, 1, 2 and 6) were metacognitive strategies, whereas two others (items 7 and 15) were cognitive strategies. But all the five least frequent strategies were metacognitive strategies, particularly evaluating strategies. Further digging into the data indicated that almost all the cognitive strategies fell into the high usage level. However, only six of the metacognitive strategies went to the high usage level. Among the three subscales within metacognitive strategies, planning strategies fell into the high usage level. Nonetheless, all of the monitoring and evaluating strategies went into the medium usage level; except two evaluating strategies that went into the low usage level. Table 2 presents an overall picture of strategy use by participants in this study.

Table 2. Descriptive statistics for the cognitive and metacognitive strategy use

\begin{tabular}{|l|l|l|c|}
\hline \multirow{5}{*}{ EFL reading performance } & \multicolumn{1}{|c|}{ Success } & Mean & \multicolumn{1}{c|}{ SD } \\
\cline { 2 - 4 } & High-proficiency & 4.258 & .258 \\
\cline { 2 - 4 } & Moderate-proficiency & 3.628 & .386 \\
\cline { 2 - 4 } & Low-proficiency & 2.708 & .320 \\
\hline \multirow{5}{*}{ Cognitive strategies } & High-proficiency & 4.422 & .261 \\
\cline { 2 - 4 } & Moderate-proficiency & 3.861 & .546 \\
\cline { 2 - 4 } & Low-proficiency & 2.948 & .478 \\
\hline Metacognitive strategies & High-proficiency & 4.132 & .359 \\
\cline { 2 - 4 } & Moderate-proficiency & 3.449 & .412 \\
\cline { 2 - 4 } & Low-proficiency & 2.524 & .393 \\
\hline
\end{tabular}

Table 3. Descriptive statistics by success High-proficiency test-takers reported higher use of both cognitive and

\begin{tabular}{|l|l|c|r|}
\hline Variables & Subscales & Mean & \multicolumn{1}{c|}{ SD } \\
\hline Cognitive strategies & Comprehending & 3.853 & 0.712 \\
\cline { 2 - 4 } & Memory & 3.718 & 0.869 \\
\cline { 2 - 4 } & Retrieval & 3.632 & 0.911 \\
\cline { 2 - 4 } & Overall & 3.727 & 0.690 \\
\hline Metacognitive strategies & Planning & 3.800 & 0.757 \\
\cline { 2 - 4 } & Monitoring & 3.193 & 0.851 \\
\cline { 2 - 4 } & Evaluating & 2.891 & 0.732 \\
\cline { 2 - 4 } & Overall & 3.301 & 0.667 \\
\hline
\end{tabular}

In order to answer the second research question, a factorial ANOVA test was conducted, which indicated a significant difference across the three groups, F (2, 309) $=423.356, \mathrm{p}=.001$, partial $\eta^{2}=0.733$. Table 3 presents the mean score of each group. metacognitive strategies than the moderate-proficiency testtakers, who in turn reported higher use of the strategies than their low-proficiency peers. The factorial ANOVA test results indicate a significant difference between the mean scores, as indicated in Table 4. 
Table 4. Factorial ANOVA results for success levels the best predictor of EFL reading test performance.

Additionally, Scheffe post-hoc test was conducted, which indicated a significant difference among the groups.

\section{Discussion}

\begin{tabular}{|c|c|c|c|c|}
\hline Deperidentvaristles & of & $\mathbf{F}$ & p & Partial $n^{2}$ \\
\hline EFL reading porformance & 2 & 425063 & 000 & 739 \\
\hline Cogntive strotegles & 2 & 208042 & 000 & $5 \%$ \\
\hline Metacogritive strategies & 2 & 339361 & 000 & 687 \\
\hline
\end{tabular}

The study set out to investigate EFL test-takers' reading strategy use in a standardized EFL reading test. The results indicated that they, on the whole, displayed characteristics of active strategic readers.

Table 5. Scheffe post-hoc test of differences across the success groups

Frequent use of multiple strategies may have been associated with the challenging

\begin{tabular}{|c|c|c|c|c|c|}
\hline Dependent variable & Success (I) & Success $(J)$ & $\begin{array}{c}\text { Mean } \\
\text { differences (I-J) }\end{array}$ & $\begin{array}{l}\text { Standard } \\
\text { error }\end{array}$ & p-value \\
\hline \multirow[t]{3}{*}{ EFL reading performance } & High-proficiency & Mod-proficiency & .603 & .046 & 000 \\
\hline & High-proficiency & Low-proficiency & 1.484 & .051 & 000 \\
\hline & Mod-proficiency & Low-proficiency & .881 & .044 & 000 \\
\hline \multirow[t]{3}{*}{ Cognitive strategies } & High-proficiency & Mod-proficiency & .585 & .061 & 000 \\
\hline & High-proficiency & Low-proficiency & 1.473 & .068 & 000 \\
\hline & Mod-proficiency & Low-proficiency & .887 & .058 & 000 \\
\hline \multirow[t]{3}{*}{ Metacognitive strategies } & High-proficiency & Mod-proficiency & .616 & .055 & 000 \\
\hline & High-proficiency & Low-proficiency & 1.493 & .061 & 000 \\
\hline & Mod-proficiency & Low- & .876 & .052 & 000 \\
\hline
\end{tabular}

In order to address the third research question, a regression analysis test was performed with test performance as a dependent variable and reading strategies as independent variables. The standardized regression co-efficient values for all the six strategy scales were statistically significant t (305)- > 2.138, p < 0.033. The Beta values (comprehension, .082; memory, .133; retrieval, .246; planning, .224; monitoring, .181 and evaluating, .205) further indicate that retrieval and planning strategies were demands of the test, which called for students to deal with both language and test task demands. Simultaneously, frequent use of multiple strategies might be associated with English teaching and learning practices in the Nepalese classroom context. Most teachers in Nepalese schools give explicit explanations when teaching English grammar, vocabulary and discourse structures. Thus, classroom instructions could help students develop awareness about English reading strategies, and this might have contributed to 
facilitating students' awareness of reading strategies in English (Zhang \& Wu, 2009).

With regard to the use of cognitive and metacognitive strategies, consistent with Phakiti's (2003) findings, test-takers reportedly used more cognitive strategies than metacognitive strategies. However, the results did not corroborate Song and Cheng's (2006) claim that EFL learners use more metacognitive strategies than cognitive strategies. Nevertheless, the differences between the current study and Song and Cheng's study should be considered. For instance, Song and Cheng employed Purpura's (1999) reading strategy questionnaire but this study employed Phakiti's (2008) questionnaire. The two questionnaires differ in terms of the number of items and the subscales of reading strategies. Additionally, the current study was conducted in the Nepalese context but Song and Cheng's study was in the Chinese context. Therefore, there might have been some effects of testtakers' academic background and native language on strategy use ( Zhang \& Wu, 2009).

A closer look at the strategy use at the subscale level indicates that comprehension strategy was reportedly used with the highest frequency. It might be plausible to interpret the finding in relation to English teaching and testing practices in Nepalese public schools. Very similar to the Chinese context (Zhang \& Wu, 2009), most English teachers in Nepal employ a comprehensiontesting type of teaching strategy and they mostly use comprehension passages to test their students. Those comprehension exercises may offer opportunities for students to be aware of various comprehension strategies in reading and to practice using those strategies. As a result, it is possible that participants learnt comprehension strategies through their experience of doing comprehension-testing exercises in their classroom contexts. However, this does not mean that text comprehension-oriented teaching and testing practice is good enough to enhance EFL proficiency. There might also be a case that the strategies they used during the test might be simply test-taking strategies, which are different from reading comprehension strategies for effective reading. Those test-taking strategies might have helped them to perform well in their test without necessarily improving their proficiency for in-depth understanding of the reading materials (Cohen, 1998). This aspect of teaching and testing practice needs further investigation.

Among the five most frequently reported strategies, three (Item 1, 2, and 6) involved task planning; one (Item 7) was concerned with comprehending the material (i.e. understanding the relationships between the ideas in the text and tasks), and another (Item 11) was concerned with interpreting the hidden meaning of the text. The result might suggest that EFL learners tend to plan their performance and also use comprehension and memory strategies to comprehend EFL texts.

The five least used strategies were all evaluating strategies. Two main reasons might account for this finding. Firstly, time constraints to complete the test might have impacted on the use of those strategies. Participants might have been in a rush to complete the test and they might not have got enough opportunity to evaluate their own performance. Secondly, strategy use might be associated with participants' proficiency level in English. Only a few participants $(22.12 \%)$ were high- 
proficiency learners. Low-proficiency participants might have been discouraged from using evaluation strategies because of the lack of evaluation skills or knowledge in English. For instance, item number 30 (I immediately corrected my understanding or performance mistakes when found) was the least frequent strategy among the 30 strategies included in the questionnaire. It is likely that low-proficiency participants might have been discouraged from using this strategy thinking that they would be unable to correct their answers. In other words, those low-proficiency learners had low appraisal confidence (Phakiti, 2016) to use evaluation strategies.

Consistent with the findings of some previous studies (e.g Aryadoust \& Zhang, 2016; Phakiti, 2003; Zhang \& Zhang, 2013), high-proficiency participants reportedly used more strategies than moderateproficiency participants, who in turn reported using more strategies than their low-proficiency peers. This finding suggests that "skilled readers are distinguished from unskilled readers by their conscious awareness of strategic reading processes and their actual use of reading strategies" (Zhang et al., 2014, p.77). However, the results did not corroborate Purpura's (1997, 1998) argument that low performers use more strategies than high performers.

Furthermore, consistent with Phakiti's (2003) findings, the overall results indicated a very strong relationship between strategy use (both cognitive and metacognitive) and the test performance. Additionally, it was found that each of the six strategy categories had strong relationship with the SEE reading test performance. Nevertheless, retrieval and planning strategies were the best predictors of the test performance. However, it should be noted that there are a number of reasons to be cautious in interpreting this finding. Three are outlined here before considering the limitations of the study. Firstly, caution is needed in interpreting the findings because reading comprehension in a foreign language may depend on a number of cognitive and non-cognitive factors. These include reading proficiency and grammar proficiency (Purpura, 1997, 1998), vocabulary, morphology and syntax (Kunnan, 1998), learners' language proficiency (Bachman \& Palmer 2010), individuals' working memory capacity (Robinson, 2001), the levels of linguistic thresholds in a particular context of language use (Cummins, 2000), reading attitude (Kim, 2016), test tasks, task difficulty, task demands and constraints (McNamara, 1996), test-takers' native language, gender, culture, attitude, and learning styles (see, Kunan, 1998, for detail). The second reason for caution in the interpretation of the findings relates to the level of anxiety that students would have experienced. In this study, students were told to treat the test like a real test and most of the SEE exam rules were followed. However, the level of anxiety might still have been higher in a real test situation, which might, in turn, have had an effect on strategy use as claimed by Alderson (1990). Thirdly, there might be some issues regarding the participants' understanding of the reading strategies presented to them. Although the pilot study indicated that most students had similar understanding of the strategies, there might be a case that students with different background interpreted those strategies differently.

It might be equally important to examine the nature of cognitive and metacognitive strategies in relation to the test 
performance. The strategies might need to be viewed as two interactive facets of the same mental processes that do not occur independently of each other. There are difficulties in distinguishing cognitive strategies from metacognitive strategies as they may overlap in some contexts (Bax, 2013). The same strategy can be considered as either a cognitive or a metacognitive strategy depending on the purpose for using that strategy. For instance, one of the items in the test requires test-takers to read the text and order the given sentences correctly. In this context, one might go back to the text to find out those statements as a scanning strategy (cognitive strategy), or as a way of checking answers or making sure that the sentences are correctly ordered (metacognitive). Therefore, as Phakiti (2003) argues, "the same strategy in one occasion may be cognitive while in another occasion it may be metacognitive" (p.43), suggesting that participants could have some difficulties to make decisions with regard to their strategy use.

\section{Limitations of the Study}

The study has revealed some interesting findings with regard to reading strategy use in the SEE reading test. However, they are certainly not conclusive or comprehensive. Given the vague nature of reading strategies, the relationship between strategy use and the test performance could have been much more complicated than what has been found (Song \& Cheng, 2006). Therefore, this study may have a number of limitations. The first limitation concerns accuracy of the reading strategy questionnaire used in the study as it may have failed to capture the full array of complicated mental processes that the testtakers went through when taking the test. The second limitation concerns the reliability of the questionnaire responses. Although test-takers reported high usage of the available reading strategies, it is hard to know whether they were actually using those strategies. Another limitation concerns its sample size, which was limited to 312 students from Nepalese public schools. This may limit the generalization of the results to other circumstances. Future research in this area with a larger sample obtained from the same or similar population or learning conditions is recommended to validate the results of the current study.

\section{Implications of the Study}

The study has some practical implications for classroom instruction. The study found a strong relationship between strategy use and the test performance. This finding might indicate that EFL reading is not only a language problem but also a reading problem, as argued by Alderson (1984) and Carrell (1991). Thus, it might be plausible to argue that informed training on reading strategy use can be useful in helping EFL learners enhance their reading proficiency, with a potential of leading to improvement in their overall English proficiency (Zhang $\& W u, 2009)$. Therefore, what EFL teachers need to do is to find out whether their students are aware of different reading strategies and/or how effectively they are using those strategies. Then, teachers need to give them guidance accordingly. It seems that poor learners need more help in increasing their knowledge about strategy use. Teachers in EFL classrooms need to take into consideration timely provision of reading strategies in their instruction as strategy-based instruction is expected to contribute to autonomous reading behaviors (Aghaie \& Zhang, 2012) and high achievement in the target language. It can 
be hypothesized that low-proficiency learners will benefit from an informed strategy training course that guides them to think about their reading processes, identify their weaknesses, and take remedial measures, as suggested by some researchers who have reported positive effects of strategy training on EFL and/or ESL learning (Aghaie \& Zhang, 2012; Lee, 2007; Mardi, 2013; Salataci \& Akyel, 2002).

\section{Conclusion}

The study was carried out to investigate the reading strategies used in the SEE reading test and also to investigate the relationship between strategy use and the test performance. The findings of this study reveal that the Nepalese EFL learners are active strategy users; they used more cognitive strategies than metacognitive strategies. The study also indicated a close relationship between strategy use and the SEE test performance. This means, a higher level frequency of strategy use corresponds to better test performance. Thus, using reading strategies seems to affect EFL tests performance. Retrieval and planning strategies at the subscale level were the best predictors of their SEE test performance. However, it should be noted that learners, in other contexts, "might use different strategies with different test tasks" (Song \&Cheng, 2006, p.260).

The study has some practical implications for EFL reading-strategy instruction in the Nepalese context or in other educational settings that share similar characteristics. First, high proficiency learners seem to be distinguished from their low-proficiency counterparts in terms of their strategic knowledge. Therefore, the study advocates for an incorporation of explicit strategy training into the usual reading instruction procedures. Besides using comprehensiontesting exercises, it seems necessary to make EFL students, particularly lowproficiency students, aware of reading strategies. The major focus is ascribed to evaluation strategies (the least used strategies) and retrieval strategies (the best predictor of EFL test performance). However, due to some limitations associated with the methods of the study, the generalization of the findings to the entire SEE test-takers or to other reading tests might be restricted. Additionally, EFL test performance might also be affected by several other factors such as gender, cultural background, learner attitude, and motivation. Therefore, it is recommended that more research is carried out to validate the findings of the study and to obtain an all-inclusive picture of the relationship between learners' variables and EFL test performance in various cultural settings.

\section{References}

Alderson, J. C. (1990). Testing reading comprehension skills (part 2). Reading in a Foreign Language, 7(1), 465-503.

Aghaie, R., \& Zhang, L. J. (2012). Effects of explicit instruction in cognitive and metacognitive reading strategies on Iranian EFL students' reading performance and strategy transfer. Instructional Science, 40(6), 1063-1081. https://doi.org/10.1007/s11251-0119202-5

Aryadoust, V., \& Zhang, L. (2016). Fitting the mixed Rasch model to a reading comprehension test: Exploring individual difference profiles in L2 reading. Language Testing, 33(4), 529553. https://doi.org/10.1177/ 0265532215594640 
Bachman, L. F., \& Palmer, A. S. (2010). Language testing in practice. Oxford, UK: Oxford University Press.

Bernhardt, E. (1991). Reading development in a second language: Theoretical research and classroom perspectives. Norwood, NJ: Ablex.

Cohen, A. D. (2006). The coming of age of research on test-taking strategies. Language Assessment Quarterly, 3(4), 307-331.

Cohen, A. D., \& Upton, T. A. (2007). I want to go back to the text: Response strategies on the reading subtest of the new TOEFL(R). Language Testing, 24(2), 209-250. https://doi.org/10.1177/ 0265532207076364

Cohen, A. D., \& Upton, T. A. (2006). Strategies in responding to the new TOEFL reading tasks (Mono- graph No. 33). Princeton, NJ: ETS, Retrieved October 20, 2016, from http:// www.ets.org.

Cummins, J. (2000). Language, power and pedagogy: Bilingual children in the crossfire. Clevedon: Multilingual Matters.

Dawadi, S. (2015). Reading strategies in the Nepalese School Leaving Exam: Establishing Construct Validity. An unpublished Master's Dissertation. England: The Open University.

Ghaemi, H., \& Ghaemi, H. (2011). Application of structural equation modeling in assessing the relationship between stuttering students' cognitive and metacognitive strategies and their reading comprehension performance. Language Testing in Asia, 1(2), 7-32.
Kim, H. (2016). The relationships between Korean university students' reading attitude, reading strategy use, and reading proficiency. Reading Psychology, 37(8), 1162-1195. https:/ / d o i.o r g / $10.1080 /$ 02702711.2016.1193581

Kunnan, A. J. (1998). Approaches to validation in language assessment. In A. J. Kunnan (Ed.), Validation in language assessment (pp. 1-16). Mahwah, NJ: Lawrence Erlbaum Associates, Inc.

McNamara, T. (1996). Measuring second language performance. London: Longman.

Phakiti, A. (2016). Test-takers' performance appraisals, appraisal calibration, and cognitive and metacognitive strategy use. Language Assessment Quarterly, 13(2), 75-108. https://doi.org/ 10.1080/15434303.2016.1154555

Phakiti, A. (2008). Construct validation of Bachman and Palmer's (1996) strategic competence model over time in EFL reading tests. Language Testing, 25 (2), 237-272. https://doi.org/ $10.1177 / 0265532207086783$

Phakiti, A. (2003). A closer look at the relationship of cognitive and metacognitive strategy use to EFL reading achievement test performance. Language Testing, 20(1), 26-56. https://doi.org/10.1191/ 02655322031t243oa

Purpura, J. E. (1999). Learner strategy use and performance on language tests: A structural equation modeling approach. Cambridge, UK: Cambridge University Press. 
Purpura, J. E. (1997). An analysis of the relationships between test-takers' cognitive and metacognitive strategy use and second language test performance. Language Learning, 42(2), 289-325.

Robinson, P. (2001). Task complexity, task difficulty, and task production: Exploring interactions in a componential framework. Applied Linguistics, 22(1), 27-57. https:/ / doi.org/10.1093/applin/22.1.27

Song, X., \& Cheng, L. (2006). Language learner strategy use and test performance of Chinese learners of English. Language Learning, 4303(909703600), 37-41. https:// doi.org/10.1207/s15434311laq0303

Sungatullina, D. D., Zalyaeva, E. O., \& Gorelova, Y. N. (2016). Metacognitive awareness of TOEFL reading comprehension strategies. SHS Web of Conferences, 26. https:/ / doi.org/http:/ /dx.doi.org/10.1051/shsconf/ 20162601046

Yayli, D. (2010). A think-aloud study: Cognitive and metacognitive reading strategies of ELT Department students. Eurasian Journal of Educational Research, (38), 234-251.

Zhang, L., Aryadoust, V., \& Zhang, L. J. (2014). Development and validation of the test- takers' metacognitive awareness reading questionnaire (TMARQ). Asia-Pacific Education Researcher, 23(1), 37-51. https:// doi.org/10.1007/s40299-013-0083-z

Zhang, L., Goh, C. C. M., \& Kunnan, A. J. (2014). Analysis of test-takers' metacognitive and cognitive strategy use and EFL reading test performance: A multi-sample SEM approach. Language Assessment Quarterly, 11(1), 76-102. https://doi.org/10.1080/ 15434303.2013.853770

Zhang, L. J., \& Wu, A. (2009). Chinese senior high school EFL students' metacognitive awareness and reading-strategy use. Reading in a Foreign Language, 21(1), 37-59.

Zhang, L., \& Zhang, L. J. (2013a). Relationships between Chinese college test-takers' strategy use and EFL reading test performance: a structural equation modeling approach. RELC Journal, 44(1), 35-57. https:/ / doi.org/ $10.1177 / 0033688212463272$

Zhang, W., Liu, M., Zhao, S., \& Xie, Q. (2011). English test-taking strategy use and students' test performance. Asian EFL Journal, 13(2), 133-168.

\section{Contributor}

Mrs Saraswati Dawadi is currently a PhD student at the Open University, England, researching into the power of the Secondary Education Examination English test in Nepal with a particular focus on the impacts of the letter grading system on students and parents. She has earned master's degree in ELT from Tribhuvan University, Nepal, and MA: TESOL from Lancaster University, England, as a Hornby Trust Scholar 2013/2014. Prior to starting her study in England, she was a lecturer at Tribhuvan University, Nepal. Her interest sits broadly within language assessment, second language acquisition and English language teaching. 


\section{Appendix A}

\section{Cognitive and metacognitive questionnaire}

\section{Part One: Some information about you}

ID:

Age:

Gender:

Year of the

English study (in years):

\section{Part Two: Cognitive Strategies for language learning}

A number of statements which people use to describe themselves when they were taking a reading test are given below. Read each statement and indicate how you take the SLC reading test. Choose 1 (Never), 2 (Sometimes), 3 (Often), 4 (Usually), and 5 (Always).

\begin{tabular}{|c|c|c|c|c|c|}
\hline Your thinking & & $\mathrm{ca}$ & & & \\
\hline I planned what to do before I began to complete this reading test. & 1 & & & & 5 \\
\hline 2. I made sure I clarified the goals of the reading test tasks. & 1 & 2 & 3 & 4 & 5 \\
\hline 3. I considered essential steps needed to complete the reading test. & 1 & 2 & 3 & 4 & 5 \\
\hline 4. I made sure I understood what had to be done and how to do it. & 1 & 2 & 3 & 4 & 5 \\
\hline 5. I knew what to do if my intended plans did not work efficiently while completing this & & & & & \\
\hline reading test. & 1 & 2 & 3 & 4 & 5 \\
\hline 6. I flipped through the reading test before I actually started to complete it. & 1 & 2 & 3 & 4 & 5 \\
\hline 7. I tried to understand the relationships between ideas in the text and tasks. & 1 & 2 & 3 & 4 & 5 \\
\hline 8. I tried to understand the content of the text and tasks without looking up every word. & 1 & 2 & 3 & 4 & 5 \\
\hline 9. I thought what was going to happen next while I was reading the text. & 1 & 2 & 3 & 4 & 5 \\
\hline 10. I analyzed what the author meant or tried to say in the text. & 1 & 2 & 3 & 4 & 5 \\
\hline 11. I tried to interpret hidden ideas/meanings in the texts. & 1 & 2 & 3 & 4 & 5 \\
\hline 12. I translated the text, tasks or questions into my first language. & 1 & 2 & 3 & 4 & 5 \\
\hline 13. I summarized the main information in the text. & 1 & 2 & 3 & 4 & 5 \\
\hline 14. I reread texts or tasks several times when I felt I did not understand them. & 1 & 2 & 3 & 4 & 5 \\
\hline 15. I related the information from the text or tasks to my prior knowledge or experience. & 1 & 2 & 3 & 4 & 5 \\
\hline 16. I knew which information was more or less important. & 1 & 2 & 3 & 4 & 5 \\
\hline 17. I identified or guessed meanings of unknown words using context clues. & 1 & 2 & 3 & 4 & 5 \\
\hline 18. I applied my learned grammar rules while reading and completing the reading tasks. & 1 & 2 & 3 & 4 & 5 \\
\hline 19. I guessed meanings of unknown words using root words. & 1 & 2 & 3 & 4 & 5 \\
\hline 20. I was aware of the time limitations and constraints in this test. & 1 & 2 & 3 & 4 & 5 \\
\hline 21. I knew how much of the reading and test tasks remained to be done while taking the test. & 1 & 2 & 3 & 4 & 5 \\
\hline 22. I knew when I lost concentration while completing this test. & 1 & 2 & 3 & 4 & 5 \\
\hline 23. I was aware of my ongoing thinking process. & 1 & 2 & 3 & 4 & 5 \\
\hline 24. I knew when I felt worried, tense or unmotivated to complete this reading test. & 1 & 2 & 3 & 4 & 5 \\
\hline 25. I checked if I understood the texts and reading tasks. & 1 & 2 & 3 & 4 & 5 \\
\hline 26. I knew when I should read or complete the test more quickly or carefully. & 1 & 2 & 3 & 4 & 5 \\
\hline 27. I double-checked my reading comprehension or performance. & 1 & 2 & 3 & 4 & 5 \\
\hline 28. I immediately corrected my misunderstanding or performance mistakes when found. & 1 & 2 & 3 & 4 & 5 \\
\hline 29. I evaluated my plans or goals of my reading tasks constantly. & 1 & 2 & 3 & 4 & 5 \\
\hline 30. I checked my own performance and progress as I moved along the test tasks. & 1 & 2 & 3 & 4 & 5 \\
\hline
\end{tabular}

(Adapted from Phakiti, 2008) 